\title{
Ethylenediurea (EDU) Affects the Growth of Ozone-Sensitive and Tolerant Ash (Fraxinus excelsior) Trees under Ambient $\mathrm{O}_{3}$ Conditions
}

\author{
Elena Paoletti ${ }^{1, *}$, Nicla Contran ${ }^{2}$, William J. Manning ${ }^{3}$, and Francesco \\ Tagliaferro $^{4}$ \\ ${ }^{1}$ IPP-CNR, Via Madonna del Piano 10, I-50019 Sesto Fiorentino, Florence, Italy; \\ ${ }^{2}$ Department of Environmental Sciences, University of Milano-Bicocca, Piazza della \\ Scienza 1, Milan, Italy; ${ }^{3}$ Department of Plant, Soil and Insect Sciences, University of \\ Massachusetts, Amherst, MA 01003-9320; ${ }^{4}$ IPLA, Corso Casale 476, I-10128 Turin, \\ Italy \\ E-mail: e.paoletti@ipp.cnr.it
}

Received December 14, 2006; Revised December 14, 2006; Accepted December 15, 2006; Published March 21, 2007

\begin{abstract}
Adult ash trees (Fraxinus excelsior L.), known to be sensitive or tolerant to ozone, determined by presence or absence of foliar symptoms in previous years, were treated with ethylenediurea (EDU) at $\mathbf{4 5 0}$ ppm by gravitational trunk infusion over the 2005 growing season (32.5 ppm h AOT40). Tree and shoot growth were recorded in May and September. Leaf area, mycorrhizal infection, and leaf and fine root biomass were determined in September. EDU enhanced shoot length and diameter, and the number and area of leaves, in both $\mathrm{O}_{3}$-sensitive and tolerant trees. However, no EDU effects were recorded at the fine root and tree level. Therefore, a potential for EDU protection against $\mathrm{O}_{3}$-caused growth losses of forest trees should be evaluated during longer-term experiments.
\end{abstract}

KEYWORDS: European ash, ethylenediurea, forest, growth, mycorrhizae, tropospheric ozone

\section{INTRODUCTION}

Much has been written about the effects of $\mathrm{O}_{3}$ on growth of forest trees, but conclusive proof that ambient levels of $\mathrm{O}_{3}$ affect growth of forest trees remains elusive, usually because the experimental techniques do not allow extrapolation to realistic conditions[1]. Ethylenediurea (N-[2-(2-oxo-1-imidazolidinyl)ethyl]-N'phenylurea), abbreviated as EDU, used as a foliar spray or soil/potting medium drench, is systemic and persistent in plants, and has been used to prevent foliar $\mathrm{O}_{3}$ injury and determine $\mathrm{O}_{3}$ effects on growth and yield of many herbaceous plants[1,2,3] and some woody plants[4,5,6,7,8,9,10,11,12]. Gravitational trunk infusion of EDU has been demonstrated to prevent foliar $\mathrm{O}_{3}$ injury on sensitive ash (Fraxinus excelsior L.) trees[13]. We report here additional results from the same field experiment where adult trees, considered to be either $\mathrm{O}_{3}$-sensitive or -tolerant, were gravitationally infused with EDU to determine effects on tree, shoot, and fine root growth. 


\section{MATERIALS AND METHODS}

Six $\mathrm{O}_{3}$-sensitive (symptomatic) and six $\mathrm{O}_{3}$-tolerant (asymptomatic) adult ash trees, determined by presence or absence of foliar symptoms in previous years, were gravitationally infused with $450 \mathrm{ppm}$ ethylenediurea (EDU) or water at 3-week intervals from May to September, 2005. AOT40 over the period was $32.5 \mathrm{ppm} \mathrm{h.}$ The experimental site was located at the 34-ha "Millerose" park in Turin, Italy. Details about infusion methodology, site characteristics, and EDU protection from $\mathrm{O}_{3}$ visible injury are presented elsewhere[13].

Measurements of tree and shoot growth were carried out in May and September, while biomass, leaf area, and fine root mycorrhizal infection were determined only in September. Tree diameter was measured at breast height by means of a calliper. The points of measurements were labelled to reduce the error from May to September. Tree height was measured with a clinometer (Model CM360PA, Silva, Sweden). Shoot growth was measured on one 1-year-old sun shoot per tree, from the lower crown part. The shoots were the terminal ones of a lateral branch and were randomly selected. The total number of leaves and leaflets per shoot was counted. Shoot length and base diameter were recorded by means of a ruler and a digital calliper, respectively, with 0.1-mm accuracy. In September, 3 shoots per plant were collected. Total leaflet area per shoot was determined with an AM300 area meter (ADC, BioScientific Ltd, Herts UK). Shoot biomass was determined by oven-drying at $65^{\circ} \mathrm{C}$ until a constant weight was reached. Leaflet mass per unit of leaflet area (LMA) and leaflet water content (LWC = (fresh weight-dry weight)/dry weight) were calculated

Fine roots (diameter $<2 \mathrm{~mm}$ ) were sampled in standard cores of soil $(500 \mathrm{ml})$. Four cores per tree were collected $40 \mathrm{~cm}$ far from the trunk along the cardinal points and joined in a single sample. Roots were attributed to $F$. excelsior with the help of morphological and anatomical observations[14]. F. excelsior fine roots were analyzed with a Wild M8 (16x) stereomicroscope by means of the gridline intersect method[15] adapted to ectomycorrhizae[16]. Infected, dead and total tips were counted. Fine root length was determined using the Newman's formula[17]. Fine root biomass, after careful rinsing with tap water for removal of adhering soil particles, was determined by oven-drying at $65^{\circ} \mathrm{C}$ until a constant weight was reached.

The statistical unit was the single tree. After checking for normality, data were analyzed using a twoway (EDU $x$ tree Oz-sensitivity) analysis of variance (Statistica 6.0, StatSoft, Tulsa, OK).

\section{RESULTS}

EDU significantly reduced the abscission of leaves and induced a larger increment of the shoot length and diameter over the growing season, compared to the water-infused trees (Table 1). The $\mathrm{O}_{3}$-sensitive trees had higher DBH increment and leaf abscission than the $\mathrm{O}_{3}$-tolerant trees. EDU increased the leaf area and decreased the leaflet water content (Table 2). The latter effect was due to the LWC strong reduction in the $\mathrm{O}_{3}$-sensitive trees. No EDU effect was recorded at the fine root level (Table 3). The $\mathrm{O}_{3}$-sensitive trees showed lower fine root biomass and length, and thus less tips than the tolerant trees. 
TABLE 1

Means ( \pm SE) and Levels of Significance of a Two-Way ANOVA for the Effects of EDU (Water vs. EDU-Infused Trees) and Tree $\mathrm{O}_{3}$ Sensitivity (Symptomatic vs. Asymptomatic) on the Increments (September vs. May) in: Diameter at Breast Height (DBH), Tree Height (H), Leaf Number per Shoot (Leaf No.), Leaflet Number per Shoot (Leaflet No.), Shoot Length (SL), and Shoot Diameter (SD), in Adult Fraxinus excelsior Trees

\begin{tabular}{llllllll}
\hline Infusion & $\begin{array}{l}\text { Tree } \\
\text { Sensitivity }\end{array}$ & $\begin{array}{l}\text { DBH } \\
\text { Increment } \\
(\%)\end{array}$ & $\begin{array}{l}\mathrm{H} \\
\text { Increment } \\
(\%)\end{array}$ & $\begin{array}{l}\text { Leaf No. } \\
\text { Increment } \\
(\%)\end{array}$ & $\begin{array}{l}\text { Leaflet No. } \\
\text { Increment } \\
(\%)\end{array}$ & $\begin{array}{l}\text { SL } \\
\text { Increment } \\
(\%)\end{array}$ & $\begin{array}{l}\text { SD } \\
\text { Increment } \\
(\%)\end{array}$ \\
\hline & & & & & & & \\
EDU & Symptomatic & $8.0 \pm 1.8$ & $2.5 \pm 2.5$ & $-6.2 \pm 2.3$ & $-7.9 \pm 1.7$ & $17.5 \pm 8.8$ & $11.1 \pm 2.7$ \\
EDU & Asymptomatic & $2.0 \pm 0.8$ & $1.1 \pm 1.0$ & $1.8 \pm 0.9$ & $\begin{array}{l}2.8 \pm 2.5 \\
17.5 \pm 5.5\end{array}$ & $15.3 \pm 0.2$ \\
WATER & Symptomatic & $5.1 \pm 2.7$ & 0 & $-7.7 \pm 1.0$ & $-10.6 \pm 1.9$ & $6.7 \pm 1.2$ & $6.0 \pm 2.0$ \\
WATER & Asymptomatic & $1.0 \pm 0.9$ & $2.4 \pm 4.0$ & $-2.8 \pm 3.5$ & $-6.9 \pm 2.4$ & $7.7 \pm 4.4$ & $4.6 \pm 2.5$ \\
& & & & & & & \\
\hline EDU & & 0.182 & 0.898 & $0.036^{*}$ & 0.100 & $0.060+$ & $0.024^{*}$ \\
Tree Sensitivity & $0.047^{*}$ & 0.577 & $0.005^{* *}$ & 0.120 & 0.194 & 0.730 \\
EDU x Tree Sensitivity & 0.868 & 0.372 & 0.860 & $0.061+$ & 0.083 & 0.506 \\
\hline
\end{tabular}

${ }^{* * *}, P \leq 0.001 ;{ }^{* *}, P \leq 0.01 ;{ }^{*}, P \leq 0.05 ;+, P \leq 0.1 ; \mathrm{NS}, P>0.1$.

TABLE 2

Means ( \pm SE) and Levels of Significance of a Two-Way ANOVA for the Effects of EDU (Water vs. EDU-Infused Trees) and Tree $\mathrm{O}_{3}$ Sensitivity (Symptomatic vs. Asymptomatic) on: Total Leaf Area and Biomass, Leaflet Mass per Unit Leaflet Area (LMA) and Leaflet Water Content (LWC) in Shoots of Adult Fraxinus excelsior Trees Measured at the End of the Growing Season

\begin{tabular}{llllll}
\hline Infusion & $\begin{array}{l}\text { Tree } \\
\text { Sensitivity }\end{array}$ & $\begin{array}{l}\text { Total Leaf } \\
\text { Area } \\
\mathrm{cm}^{2}\end{array}$ & $\begin{array}{l}\text { Total Leaf } \\
\text { Biomass }\end{array}$ & LMA & LWC \\
\hline & & $\mathrm{g}$ & $\mathrm{mg} \mathrm{cm}^{-2}$ & $\mathrm{~g} \mathrm{H}_{2} \mathrm{O} \mathrm{g} \mathrm{leaflet} \mathrm{dw}^{-1}$ \\
EDU & Symptomatic & $1368 \pm 119$ & $13.4 \pm 3.8$ & $5.6 \pm 0.6$ & $1.64 \pm 0.12$ \\
EDU & Asymptomatic & $1483 \pm 85$ & $17.9 \pm 6.1$ & $6.2 \pm 0.8$ & $2.35 \pm 0.29$ \\
WATER & Symptomatic & $951 \pm 103$ & $9.1 \pm 2.4$ & $6.1 \pm 1.2$ & $2.67 \pm 0.29$ \\
WATER & Asymptomatic & $1181 \pm 305$ & $15.0 \pm 6.0$ & $7.4 \pm 0.4$ & $2.28 \pm 0.20$ \\
& & & & & $0.074+$ \\
\hline EDU & & $0.053+$ & 0.493 & 0.279 & 0.515 \\
Tree Sensitivity & 0.325 & 0.329 & 0.251 & $0.045+$ \\
EDU $x$ Tree Sensitivity & 0.739 & 0.895 & 0.650 & \\
\hline
\end{tabular}


TABLE 3

Means ( $\pm \mathrm{SE}$ ) and Levels of Significance of a Two-Way ANOVA for the Effects of EDU (Water vs. EDU-Infused Trees) and Tree $\mathrm{O}_{3}$ Sensitivity (Symptomatic vs. Asymptomatic) on: Biomass, Total Number of Tips, Percent of Dead Tips and Mycorrhizal Infection, and Length of Fine Roots (diameter $<2 \mathrm{~mm}$ ) in a Standard Volume $(500 \mathrm{ml})$ of Soil collected under Adult Fraxinus excelsior Trees at the End of the Growing Season

\begin{tabular}{lllllll}
\hline Infusion & $\begin{array}{l}\text { Tree } \\
\text { Sensitivity }\end{array}$ & Biomass & Total Tips & Dead Tips & $\begin{array}{l}\text { Mycorrhizal } \\
\text { Infection } \\
\%\end{array}$ & Length \\
& & No. & $\%$ & cm \\
\hline EDU & Symptomatic & $0.22 \pm 0.07$ & $163 \pm 64$ & $8.4 \pm 1.2$ & $83.5 \pm 0.1$ & $478 \pm 212$ \\
EDU & Asymptomatic & $1.20 \pm 0.59$ & $1323 \pm 549$ & $9.3 \pm 1.1$ & $81.5 \pm 0.1$ & $2530 \pm 968$ \\
WATER & Symptomatic & $0.40 \pm 0.11$ & $291 \pm 130$ & $7.5 \pm 0.1$ & $81.2 \pm 0.1$ & $839 \pm 400$ \\
WATER & Asymptomatic & $1.09 \pm 0.37$ & $727 \pm 237$ & $6.6 \pm 0.1$ & $87.0 \pm 0.1$ & $2122 \pm 1120$ \\
& & & & & & \\
\hline EDU & & 0.923 & 0.522 & 0.747 & 0.775 & 0.979 \\
Tree Sensitivity & $0.046 *$ & $0.055+$ & 0.691 & 0.628 & $0.097+$ \\
EDU $\times$ Tree Sensitivity & 0.692 & 0.332 & 0.869 & 0.564 & 0.672 \\
\hline
\end{tabular}

${ }^{* * *}, p \leq 0.001 ;{ }^{* *}, p \leq 0.01 ;{ }^{*}, p \leq 0.05 ;+, p \leq 0.1 ; \mathrm{ns}, p>0.1$.

\section{DISCUSSION}

EDU enhanced shoot length and diameter, and reduced leaf abscission. The stimulating effect of EDU on shoot growth did not translate into a stimulation of growth at the fine root and whole tree level, during one growing season. Overall, EDU effects were slight, and not enough to significantly affect the total leaf biomass. Increased growth in the EDU-treated plants over the non-EDU-treated ones has been reported in several species (Phaseolus vulgaris[18], Populus nigra[12], Trifolium subterraneum[19], Pinus taeda[8], Vigna radiata, [20] Triticum aestivum[21]).

Symptomatic trees did not show a marked reduction in growth compared to the asymptomatic trees. At the shoot level, we recorded a stimulation of leaf abscission. Part of the photosynthate may have been used to prevent or repair foliar damage rather than going toward growth[22,23], even if visible $\mathrm{O}_{3}$ injury symptoms are not necessarily correlated with adverse effects on tree growth[24,25]. In the long-term, such shifts in carbon allocation may damage the below-ground system[26] and explain why we recorded the most negative effects on the $\mathrm{O}_{3}$-sensitive fine roots. In contrast, tree diameter increased more in the $\mathrm{O}_{3}$ sensitive trees, which may be the result of their younger age (16 vs. 31 year old in sensitive and tolerant trees, respectively), although the diameter at breast height did not differ significantly (13 $\pm 1 \mathrm{~cm}$ vs. $17 \pm 5$, respectively).

In conclusion, gravitational infusion of EDU resulted in stimulation of shoot growth in both $\mathrm{O}_{3}$ sensitive and tolerant ash trees exposed to elevated ambient $\mathrm{O}_{3}$ concentrations (32.5 ppm h AOT40). Ainsworth et al.[11] found that treatment with EDU provided protection against visible injury in poplars. As no effect on growth was found, they suggested that EDU may be incapable of protecting trees against longterm damage. Our study with Fraxinus excelsior, together with studies on Gleditsia triacanthos[9], Prunus serotina[7], and Populus nigra[12], have demonstrated that EDU can provide protection against visible injury[13], as well as against growth reductions. As no effects on fine roots and tree growth were detected in one growing season, the protection of EDU on $\mathrm{O}_{3}$-impaired forest growth should be evaluated over longterm experiments. 


\section{ACKNOWLEDGMENT}

Thanks to Federica Spaziani, Mario Palenzona, Annamaria Ferrara,, Renzo Lencia, Michele Carnino, Elena Addario, and Giorgia Battaglia, who kindly provided logistic support during EDU applications and measurement campaigns; and to Regione Piemonte (project FORMEDOZONE, Interreg III B) for funding the study of ozone effects on ash.

\section{REFERENCES}

1. Manning, W.J. (2005) Establishing a cause and effect relationship for ambient ozone exposure and tree growth in the forest: progress and an experimental approach. Environ. Pollut. 137, 443-453.

2. Gatta, L., Mancino, L., and Federico, R. (1997) Translocation and persistence of EDU (ethylenediurea) in plants: the relationship with its role in ozone damage. Environ. Pollut. 96, 445-448.

3. Manning, W.J. (2000) Use of protective chemicals to assess the effects of ambient ozone on plants. In Environmental Pollution and Plant Responses. Agrawal, S.B. and Agrawal, M., Eds. Lewis Publishers, Boca Raton, FL. pp. 247-258.

4. McClenahen, J.R. (1979) Effects of ethylene diurea and ozone on the growth of tree seedlings. Plant Dis. Rep. 63, 320323.

5. Cathey, H.M. and Heggestad, H.E. (1982) Ozone sensitivity of woody plants: modification by ethylenediurea. J. Am. Soc. Hortic. Sci. 107, 1042-1045.

6. Roberts, B.R. (1987) Photosynthetic response of yellow-poplar seedlings to the antioxidant chemical ethylenediurea. $J$. Arboric. 13, 154-158.

7. $\quad$ Long, R.P. and Davis, D.D. (1991) Black cherry growth response to ambient ozone and EDU. Environ. Pollut. 70, 241254.

8. Manning, W.J., Flagler, R.B., and Frenkel, M.A. (2003) Assessing plant response to ambient ozone: growth of ozone sensitive loblolly pine seedlings treated with ethylenediurea or sodium erythorbate. Environ. Pollut. 126, 73-81.

9. Roberts, B.R., Jensen, K.F., and Cathey, H.M. (1985) Modification of ozone sensitivity in seedlings by ethylenediurea: soil application vs. stem injection. J. Am. Soc. Hortic. Sci. 110, 178-180.

10. Ainsworth, N. and Ashmore, M.R. (1992) Assessment of ozone effects on beech (Fagus sylvatica) by injection of a protectant chemical. For. Ecol. Manage. 51, 129-136.

11. Ainsworth, N., Fumagalli, I., Giorcelli, A., Mignanego, L., Schenone, G., and Vietto, L. (1996) Assessment of EDU stem injections as a technique to investigate the response of trees to ambient ozone in field conditions. Agric. Ecosyst. Environ. 59, 33-42.

12. Bortier, K., Dekelver, G., De Temmerman, L., and Ceulemans, R. (2001) Stem injection of Populus nigra with EDU to study ozone effects under field conditions. Environ. Pollut. 111, 199-208.

13. Paoletti, E., Manning, W.J., Spaziani, F., and Tagliaferro, F. (2006) Gravitational infusion of ethylenediurea (EDU) into trunks protected adult European ash trees (Fraxinus excelsior L.) from foliar ozone injury. Environ. Pollut., doi:10.1016/j.envpol.2006.05.005.

14. Agerer R. 1987-1995, Colour Atlas of Ectomycorrhizae. Einhorn-Verlag, Münich, separate pagination.

15. Giovannetti, M. and Mosse, B. (1980) An evaluation of techniques for measuring vescicular arbuscular mycorrhizal infection in roots. New Phytol. 84, 459-500.

16. Strati, S., Paoletti, E., Barbolani, E., and Pirazzi, R. (1999) Root length and distribution of Chromium in Corylus avellana with Tuber albidum mycorrhizas. Water, Air Soil Pollut. 113, 33-41.

17. Newman, E.I. (1966) A method of estimating the total length of root in a sample. J. Appl. Ecol. 3, 139-145.

18. Brunschon-Harti, S., Fangmeier, A., and Jager, H.J. (1995) Influence of ozone and ethylenediurea (EDU) on growth and yield of beans (Phaseolus vulgaris L.) in open top field chambers. Environ. Pollut. 90, 89-94.

19. Tonneijck, A.E.G. and Van Dijk, C.J. (2002) Injury and growth response of subterranean clover to ambient ozone as assessed by using ethylene diurea (EDU): three years of plant monitoring at four sites in The Netherlands. Environ. Exp. Bot. 48, 33-41.

20. Agrawal, S.B., Singh, A., and Rathore, D. (2005) Role of ethylene diurea (EDU) in assessing impact of ozone on Vigna radiata L. plants in a suburban area of Allahabad (India). Chemosphere 61, 218-228.

21. Tiwari, S., Agrawal, M., and Manning, W.J. (2005) Assessing the impact of ambient ozone on growth and productivity of two cultivars of wheat in India using three rates of application of ethylenediurea (EDU). Environ. Pollut. 138, 153160.

22. Tonneijck, A.E.G. and Van Dijk, C.J. (1997) Effects of ambient ozone on injury and yield of Phaseolus vulgaris at four rural sites in The Netherlands as assessed by using ethylenediurea (EDU). New Phytol. 135, 93-100.

23. Horton, S.J., Reinert, R.A., and Heck, W.W. (1990) Effects of ozone on three open-pollinated families of Pinus taeda L. grown in two substrates. Environ. Pollut. 65, 279-292.

24. Chappelka, A.H. and Chevone, B.I. (1992) Tree response to ozone. In Surface Level Ozone Exposures and Their Effects on Vegetation. Lefohn, A.S., Ed. Lewis Publishers, Chelsea, MI. pp. 271-309. 
25. Taylor, G.E., Jr. (1994) Role of genotype in the response of loblolly pine to tropospheric ozone: effects at the whole tree, stand and regional level. J. Environ. Qual. 13, 63-82.

26. Andersen, C.P. (2003) Source-sink balance and carbon allocation below ground in plants exposed to ozone. New Phytol. 157, 213-223.

\section{This article should be cited as follows:}

Paoletti, E., Contran, N., Manning, W.J., and Tagliaferro, F. (2007) Ethylenediurea (EDU) affects the growth of ozone-sensitive and tolerant ash (fraxinus excelsior) trees under ambient $\mathrm{O}_{3}$ conditions. TheScientificWorldJOURNAL 7(S1), 128-133. DOI 10.1100/tsw.2007.21. 

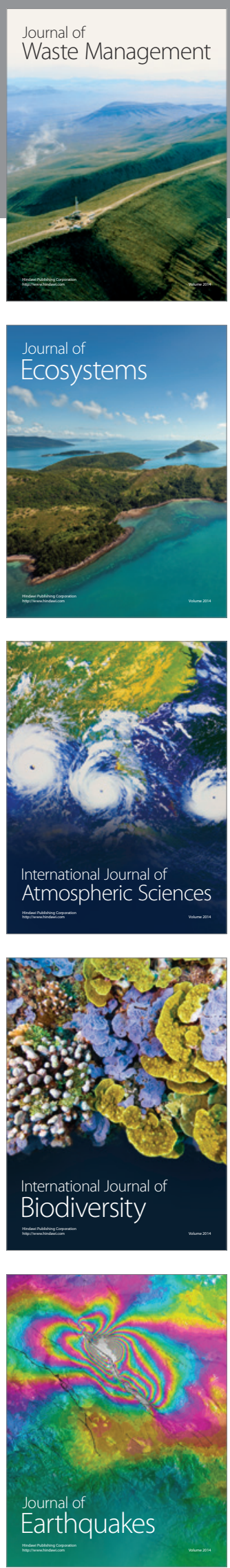
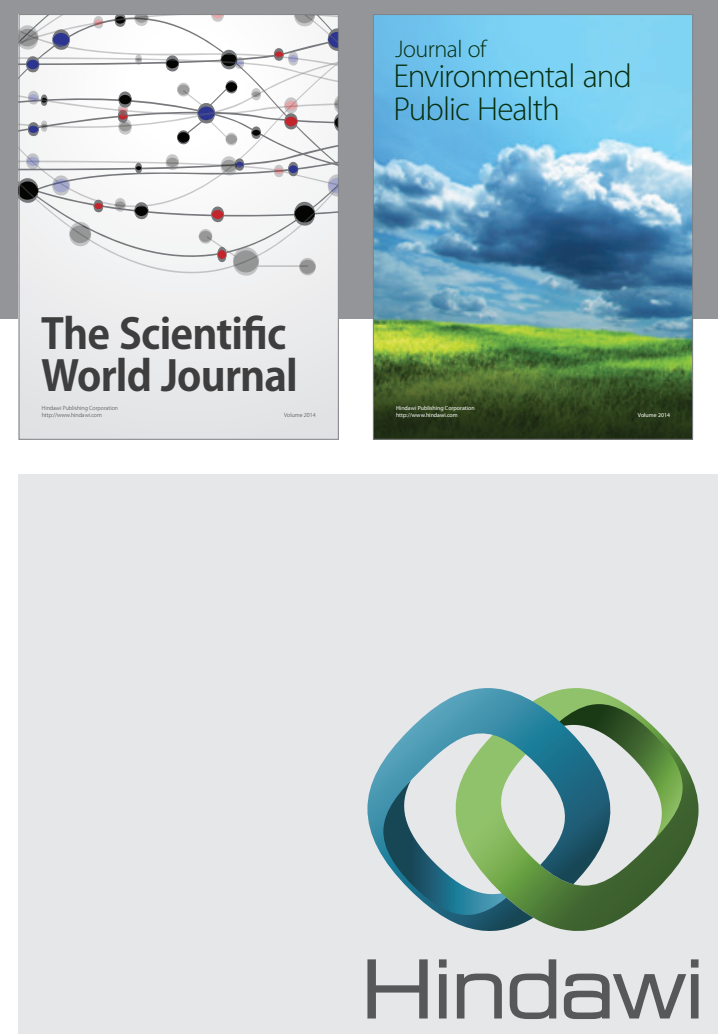

Submit your manuscripts at

http://www.hindawi.com
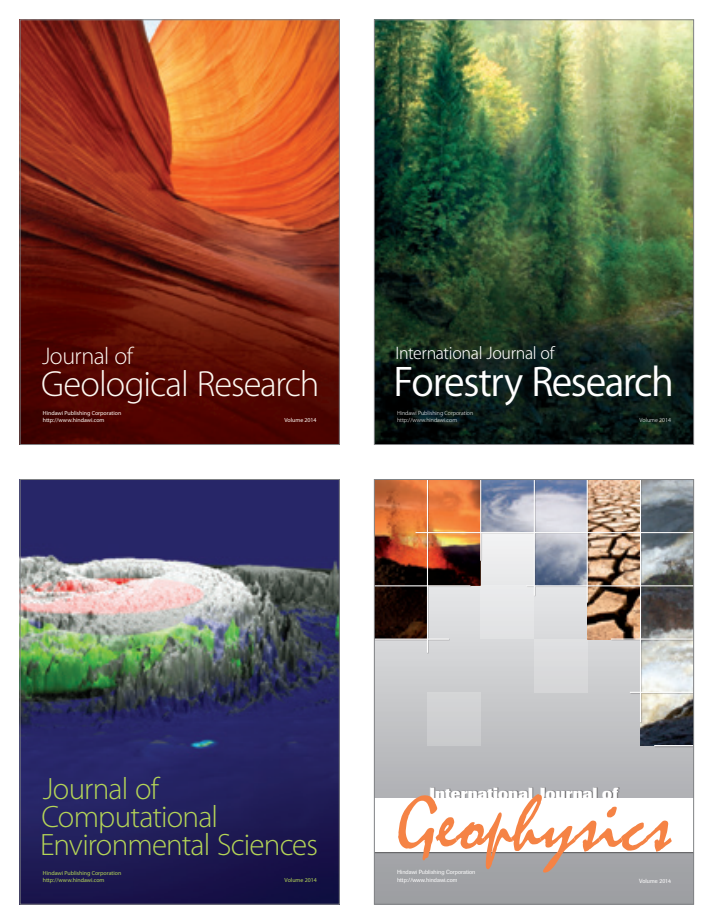
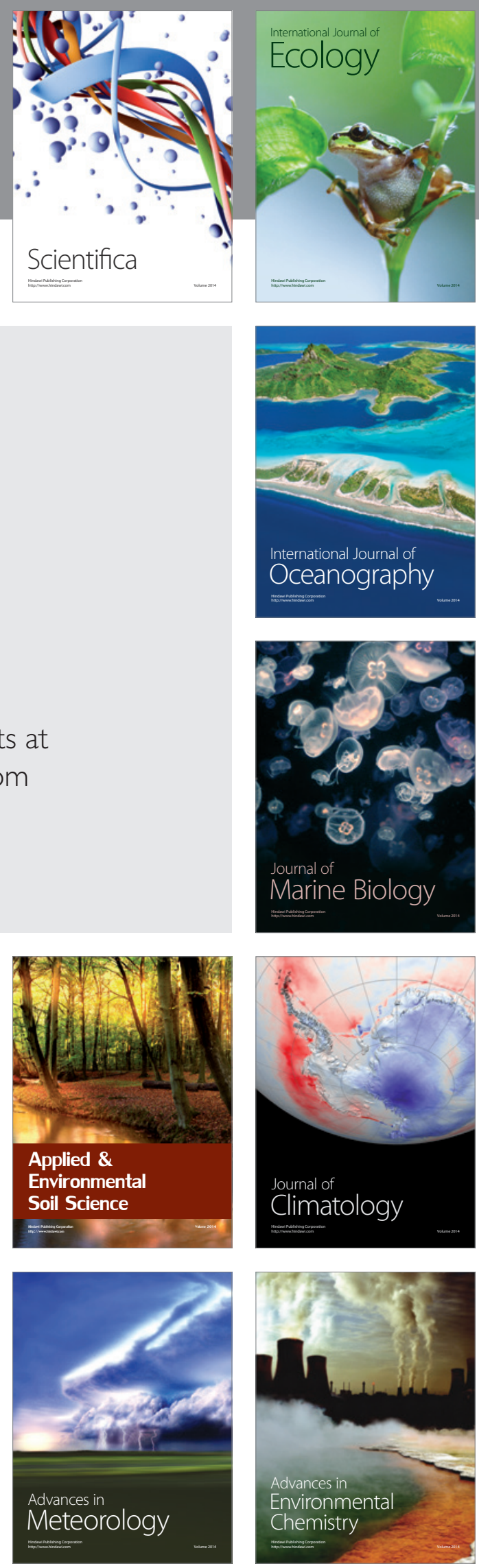